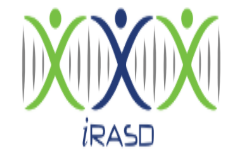

iRASD Journal of Management

Volume 3, Number 3, 2021, Pages 373 - 378

Journal Homepage:

https://journals.internationalrasd.org/index.php/jom

\title{
Academic Administrative Emotion Management: A Systematic Literature Review
}

Khalid Mahmood Khan ${ }^{1}$, Najam-ul-Kashif ${ }^{2}$

${ }^{1}$ PhD Scholar, Department of Education, The Islamia University of Bahawalpur, Bahawalpur, Pakistan. Email: khalidmahmoodkhan70@gmail.com

${ }^{2}$ Assistant Professor, Department of Education, the Islamia University of Bahawalpur, Bahawalpur, Pakistan. Email: drnajamulkashif@iub.edu.pk

\section{ARTICLE INFO}

Article History:

Received:

Revised:

Accepted:

November 18, 2021

December 29, 2021

December 30, 2021

Available Online: December 31, 2021

\section{Keywords:}

Academic Administration

Emotions

Emotion Management

Emotion Regulation

\begin{abstract}
This study investigated sociological nature of emotions with its predictors and effects through literature review. Individuals need motivational force in every field; it determines the level of effort in work. In academic field emotions of anxiety, stress, envy, challenge may affect teachers in educational institutions. Thinking approach and aptitudes can be enriched by employing simple methods like experiencing the positive emotions and taking life as an enjoyment. If employees hide their true feelings about organization, the results may affect the organizational working adversely. The investigation of emotion management impact is necessary for effective engagement of teachers. Literature revealed various intrinsic or extrinsic influential factors for the emotion management and emotion regulation. There are different models like Integrated Model of Emotional Intelligence, process Model and Ego Depletion Model. But in context Pakistan's education system the related study developed a response modulation model (URE) which will help us in stressful situations and minimizing the intensity of emotions.
\end{abstract}

(C) 2021 The Authors, Published by iRASD. This is an Open Access article under the Creative Common Attribution Non-Commercial 4.0

Corresponding Author's Email: khalidmahmoodkhan70@gmail.com

\section{Introduction}

The origin of emotion is a Latin word "Emovere". The word emovere means to help in activating different sources. The major or key elements in the human life are emotions and emotions are described as inner feeling which can be expressed in the sense of temperament, feelings, spirits, and positive gestures. Another way of expression of emotions is the rapid and hasty psychological reaction of an individual which can be observed through his behavior or attitude. Emotions and feelings move side by side. Feelings can be classified as individual's own ways of expressing the mood without any hindrances. And mood is considered as, according to psychologists and researchers, an amalgam of personal and social expressions-based mode which is in a longer span as compare to feelings and not connected with the true internal feelings of an individual. It is said that mood emerges from feelings as well emotions. As Larsen (2000) said that emotions always influence the cognition as cognitive domain works for the feelings and moods and control the human minds and others too.

When individuals are asked to talk about their work, they explain it along with their relevant feelings. They don't confine to negative feelings like stress, envy and anxiety and positive feelings like excitement, enjoyment, and pleasures. Administrative practices may promote emotions which will result in motivation or de-motivation. The phenomenon of motivation or de-motivation can be very difficultly examined in the context of educational institutions so as to know that how much the teachers are shaped with manipulating 
feelings as well as supervisory activities for the sake of motivating the students or learners. In the field of Social Psychology, the management of emotions' concept is considered as a key concept, according to Hochschild. For framing the emotion in the social context, your mood is considered a lot (Theodosius, 2006). In addition, he said that as it provides evidence how the process of socialization if performed in different social roles and apprehended under different societal rubrics as well as standards. According to Hochschild (1983), emotion is a willful physical response to an image, thought or memory. Emotion work and deep acting are interchangeable. From this point, emotion management is used for a specific phenomenon. The study of emotion management has been focused on such organizations as deal with the control of emotions. Similar is the case with education where deal of control of emotion is required as many human interactions are involved there.

Hochschild (1979) has given two main components of emotion management. These are feeling rules and evocation. It also includes the degree of expressing an emotion and also the duration of the maintenance of emotion. Evocation is that attempt in which individual's tries impar those emotions which are not already exist: vice versa will be suppression which means to eliminate or hold an actual emotion (Callahan, 2000). Damasio (1994), argues that emotion is basic prior requirement in communication of meanings to others, in making decisions and in taking actions, even after a struggle of more than hundred years. It has been observed that individuals conceal all those negative emotions which are related to their organizations. If employees hide their true feelings about organization, the results may affect the organizational working adversely (Gilley \& Coffern, 1994). Short term effect will be visible however, the organizations experience indirect or lasting possessions.

\section{Existing Available Literature}

Emotion management is a skill which improves the ability to realize, quickly accept and control one's own as well as sometimes other's feelings. This skill refers to master one's own emotions. In this concern, one must have complete authority in altering one's thoughts and feelings which are created when values are struck by an event or by the actions of a person. This helps in changing emotions and prevents from reactive out-bursts (Cleverism, 2019). Imagine the situation of a person who works hardly for many weeks on a project and in the end, he is informed that the project has been cancelled. Similarly, if a person is already overburdened with a lot of assignments is given another assignment, he will be under stress. These situations are common at workplaces. Now, how do these people react to such situations? Whether one should misbehave, shout back, sit in a corner or have excuse with the colleagues? The answer is no. such circumstance suppresses the professional efficiency and creativity of the individual. Here is the need of emotion management by developing a feeling that job cannot be done without it (Cleverism, 2019). The strategy of following the approach of stop, drop and process will help in improving emotion management skills.

\subsection{Stop}

It is an arbitrary stop for collecting the courage and emotions to develop such a strong urge for taking an action that the individual may feel hijacked. It is for thinking a strategy to do something.

\subsection{Drop}

This step demands calmness. This is the most difficult part. One cannot think properly and logically if he is over-whelmed by the emotions.

\subsection{Process}

This step is that of action. In this step one has to identify the emotions one is feeling, think about the source and find out the reason of these feelings. If one finds the source and reasons of feelings, one can do the better way, keeping in mind the goals and personal values (Cleverism, 2019). 


\section{Aim of the Study}

The presented study aimed at to develop a model of emotion management.

\subsection{Research Questions}

To achieve the aim of the study, following research questions were designed.

- How does the emotion affect individuals' activities?

- What kind of models are in practice for emotion management and regulation?

- What can be a compact model of soft skills for academic administrator to acquire emotion management?

\section{Theoretical Framework of Emotion Management}

After studying the available literature, three major models were selected for developing the emotion management model. The selected three models are, Integrated Model of Emotion Management, Process Model and Ego Depletion Model. In the following lines, these are models are described briefly.

\subsection{Integrated Model of Emotional Intelligence}

It was early 90 s of the last centuries, when emotional intelligence was considered as measurable in relation to someone's observable feelings and emotions capability, according to Salovey and Mayer who are also known as the pioneer in this field. They not only in the opined that emotional intelligence is measurable but in addition considered it to be comparable with others. Human thoughts are predictable through the human behavior, is the simple theory behind the integrated model. Mayer, Roberts, and Barsade (2008), further added that to justify it, they said there are four key abilities of emotional intelligence which are learnt by the humans from the society. These four emotional intelligence abilities are discussed in the following lines.

\subsubsection{Perceiving Emotions}

Humans by nature have the capability to recognize, judge as well as deliver or convey their feelings and emotions. At the same time, when humans recognizing, judging, and conveying their feelings and emotions, they also have the capabilities to sense and measure the feelings and emotions of others and be ready to judge them as true feelings and emotions or not. Humans do all these such activities with the help of others' gestures, language and facial expressions (Mayer \& Salovey, 1997).

\subsubsection{Reasoning with Emotions}

After perceiving the human emotions, in the second step, human develop the reasons to understand the emotions. As emotions and feelings are playing a major role in the thinking patterns. Same is the case, own human's thinking patterns are reflected when s/he observe or feel others' emotions and feelings (Mayer \& Salovey, 1997).

\subsubsection{Understanding Emotions}

The next step, after reasoning the emotions, is to understand them. Human thinking capability again utilize here by the humans and they after developing the reasoning with emotions, they try to understand their own emotions and the emotions of the others (Mayer \& Salovey, 1997).

\subsubsection{Managing Emotions}

The final stage of integrated model of emotional intelligence is to manage the human emotions. Man is very unpredictable. But human mind has the capacity and capability to predict about others' behavior and emotions through understand their emotions and 
feelings. These understandable feelings and emotions, when comes in practice, humans can manage their own emotions as well as of others too (Mayer \& Salovey, 1997).

\subsection{Ego Depletion Model}

Ego is the key part of emotions and feelings. Baumeister, Bratslavsky, Muraven, and Tice (1998) gives another model of emotional intelligence. Through ego depletion model, Baumeister and their team opined those emotions are controllable. As emotions are controllable, so, their control can be led the humans towards extreme approaches of positiveness and negative. In this context, they performed a series of experiments. Through these experiments, they try to observe the controlling of emotions, expressing of emotions in different directions, and directing the feelings and emotions as per prescribed manuals.

\subsection{Process Model}

Human emotions are interlinked with intelligence and ego in the above mentioned both models. In process model of emotions, it was tried to change the human emotions and their expression (Gross, 2001). Later John and Gross (2004) gave a model which is known as John and Gross Model of Emotions or Process Model of Emotions. This model based on two major strategies which are following.

- $\quad$ Cognitive Reconsideration which means to reconsider the incident or event in such a way as it will decrease or increase its emotional impact.

- Expressive Suppression holding the expression aptitude of humans with the one's own-self or others.

\section{Proposed Integrated Model for Emotion Management}

In Pakistan, the education system expects more about the administration. To meet the challenges of the modern world creative approach may have the potential to meet the recent dares. And such responsibility can be overcome only through the application of creative and critical thinking technique.

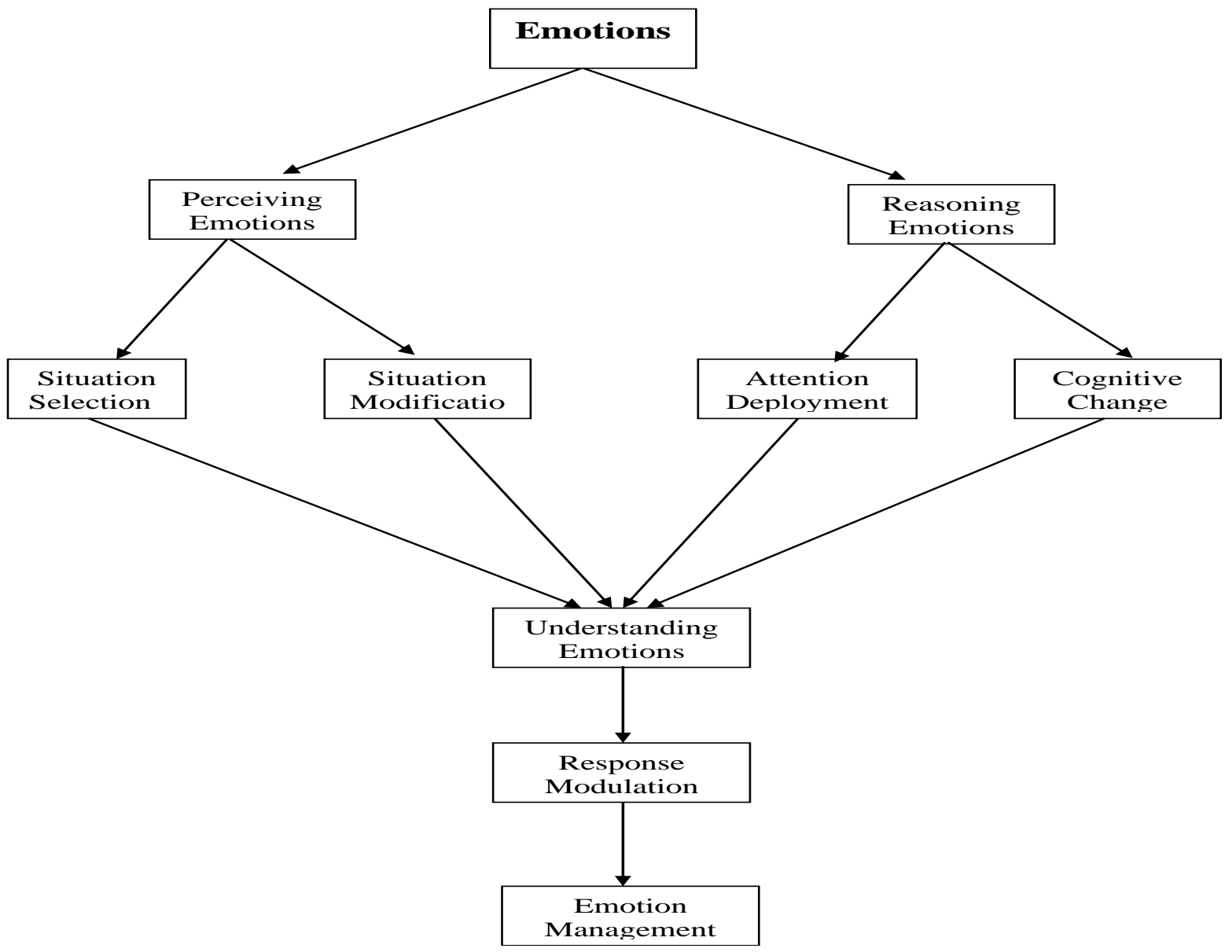




\section{Description of the Model}

For Emotion Management the basic step perceives the emotions accurately. For this step involves understanding of facial expressions, body language and all nonverbal cues. Reasoning with emotions is a cognitive process which may be in direct conflict with the inverse 'perceptional truth' but despite contrary empirical evidence an individual concludes that their emotional reaction proves something is true. Furthermore, in "Perceiving Emotions" to regulate emotions of people 'in the moment' is situation selection which means people choose challenging situations based on their likely emotional impact. Along with it an individual modifies the emotional impact of the situation which refers to situation modification. Whereas, in attention deployment an individual refocuses attention to multiple phases of a situation tries to influence emotional responses. Memory, attention, and concentration are the most commonly affected aspects of cognition and people with mood swings hardly experience any cognitive changes but for emotion management all above factors have to be aligned for understanding of emotions. In consequences will be 'Response Modulation' that will modify an emotion rather suppressing it.

\section{Conclusion}

Emotion that is an abrupt reaction to a particular event influences the cognition, physiology, and behavioral activities. The most vigilant role of emotions in human life is to organize and prioritize the daily routine tasks and activities. Therefore, decide the things that individuals reflect in their life. Emotions that are considered not harmful for wellbeing of a person can be safeguarded by avoiding certain thing to make a person conscious and cautious in future life. Positive emotions help managing stress and anxiety and creative thinking and solution of problems. Emotion management is required more in such organizations which deal with the control of emotions. In this regard education industry deals with control of emotion as many human interactions are involved there. Through extensive research literature review the phenomenon of emotion management and emotion regulation has been depicted through several models including the Ego Depletion model, Process Model, and Integrated Model of Emotional Intelligence. As focus of study was education system in Pakistan that expects from administration to meet the recent dares. And such responsibility can be fulfilled more effectively through the application of proposed model of emotion management.

\section{Suggestions}

The declining values, aggressive attitudes and increase in anxiety patients mean that there is a great need for integrating emotion management to involve academics, teacher educators, professionals, students and others for the clarification and development of a new form of education for peaceful society. For a widespread implementation of effective and appropriate education for improved knowledge, understanding and emotion management in contemporary society it will be important to monitor the continuing debates about the nature of education and potential targeted goals.

\section{References}

Baumeister, R. F., Bratslavsky, E., Muraven, M., \& Tice, D. M. (1998). Ego depletion: Is the active self a limited resource? Journal of personality and social psychology, 74(5), 1252-1265. doi:https://doi.org/10.1037/0022-3514.74.5.1252

Callahan, J. L. (2000). Emotion management and organizational functions: A case study of patterns in a not-for-profit organization. Human Resource Development Quarterly, 11(3), 245-267.

Cleverism. (2019). Emotion Management.

Damasio, A. R. (1994). Descartes' error: Emotion, rationality and the human brain. New York: Putnam, 352.

Gilley, J. W., \& Coffern, A. J. (1994). Internal consulting for HRD professionals: Tools, techniques, and strategies for improving organizational performance: Irwin Professional Publishing. 
Gross, J. J. (2001). Emotion regulation in adulthood: Timing is everything. Current directions in psychological science, 10(6), 214-219. doi:https://doi.org/10.1111/1467-8721.00152

Hochschild, A. R. (1979). Emotion work, feeling rules, and social structure. American journal of sociology, 85(3), 551-575. doi:https://doi.org/10.1086/227049

Hochschild, A. R. (1983). The Managed Heart: Commercialization Of Human Feeling.

John, O. P., \& Gross, J. J. (2004). Healthy and unhealthy emotion regulation: Personality processes, individual differences, and life span development. Journal of personality, 72(6), 1301-1334. doi:https://doi.org/10.1111/j.1467-6494.2004.00298.x

Larsen, R. J. (2000). Toward a science of mood regulation. Psychological inquiry, 11(3), 129-141. doi:https://doi.org/10.1207/S15327965PLI1103 01

Mayer, J. D., Roberts, R. D., \& Barsade, S. G. (2008). Human abilities: Emotional intelligence. Annual Review of Psychology, 59, 507-536.

Mayer, J. D., \& Salovey, P. (1997). What is emotional intelligence. Emotional development and emotional intelligence: Educational implications, 3, 31.

Theodosius, C. (2006). Recovering emotion from emotion management. Sociology, 40(5), 893-910. doi:https://doi.org/10.1177/0038038506067512 